\title{
Colon Adenomatous Polyp
}

National Cancer Institute

\section{Source}

National Cancer Institute. Colon Adenomatous Polyp. NCI Thesaurus. Code C96479.

A polypoid adenoma that arises from and protrudes into the lumen of the colon. Epithelial dysplasia is always present. According to the architectural pattern it is classified as tubular, tubulovillous, or villous. 